\title{
BAIRRO DE ANHUMAS - UMA HIPÓTESE DE BAIRRO ECOLÓGICO DENTRO DA APA CORUMBATAÍ, PERÍMETRO BOTUCATU
}

\author{
Eliana Kimoto Hosokawa ${ }^{1}$ \\ Patrícia Helen Lima²
}

1 Arquiteta e Urbanista. Especialização em Gestão e Planejamento Estratégico. Especialista em Geoprocessamento da FUNCATE. Email: li.kimoto@gmail.com

2 Arquiteta e Urbanista. Mestre em Projeto Sustentável pela FAUUSP. Doutoranda em Qualidade Ambiental pela FAUUSP. Coordenadora da Seção de Informação da Qualidade Ambiental da PM SBC E-mail: patricia.helen.lima@hotmail.com

\section{Resumo}

O presente estudo aborda desafios para a estratégia de construção de um bairro ecológico. Apresenta conceitos de sustentabilidade destacando a necessidade de mudanças na maneira de produzir, consumir e interagir com a natureza e a possibilidade de práticas para lidar com estas mudanças. Numa era de integração regional e global, situações locais são afetadas pelas dinâmicas em que estão inseridas e a gestão territorial exige inovação, análise e conhecimento. O artigo tem como objetivo questionar o uso do solo sustentável de um Bairro dentro da APA Corumbataí, Botucatu e Tejupá no perímetro de Botucatu, analisando suas diferentes escalas de influência e a hipótese de desenvolvimento de um bairro ecológico.

Palavras-chave: bairro ecológico, área de proteção ambiental, uso do solo sustentável 


\title{
NEIGHBORHOOD OF ANHUMAS - AN HYPOTHESIS IN THE ECOLOGICAL NEIGHBORHOOD WITHIN THE ENVIRONMENTAL PROTECTION AREA APA CORUMBATAÍ, PERIMETER BOTUCATU
}

\begin{abstract}
The present study approaches the challenges for the strategy of the construction of an ecological neighborhood. Presents sustainable concepts showing the necessity of changes in the manner to produce, consume and interact with nature and the possibility of practices to deal with these changes. In an era of regional and global integration, local situations are affected by the dynamics in which they are inserted and the territorial management requires innovation and knowledge analysis. The article has the mission to question the sustainable land use of a neighborhood, within the environmental protection area, APA Corumbataí, Botucatu e Tejupá in the perimeter of Botucatu city, analyzing its different scales of influence and the hypothesis of the development of an ecological neighborhood.
\end{abstract}

Keywords: ecological neighborhood, environmental protection area, sustainable land use

\section{BAIRRO DE ANHUMAS - BAIRRO NA ZONA RURAL DENTRO DA APA CORUMBATAÍ PERÍMETRO BOTUCATU}

O Bairro de Anhumas situa-se a $30 \mathrm{~km}$ da cidade de Botucatu, próximo a divisa com Bofete, formado por uma comunidade rural com cerca de 100 famílias que sobrevivem da agricultura familiar com poucos recursos tecnológicos. O isolamento e a falta de recursos político-financeiros contribuíram para que moradores de hábitos simples preservassem tradições de cultivo da terra.

A ocupação da comunidade se deu em uma região de solo fértil com rica hidrografia, às margens do Córrego Anhumas afluente do Rio Alambari. Existem importantes vias de acesso: a Rodovia Marechal Rondon, a Rodovia SP 147 (ligação da Rodovia Castelo Branco à Rodovia Marechal Rondon) e a rede ferroviária da Sorocabana (Fig. 01). 


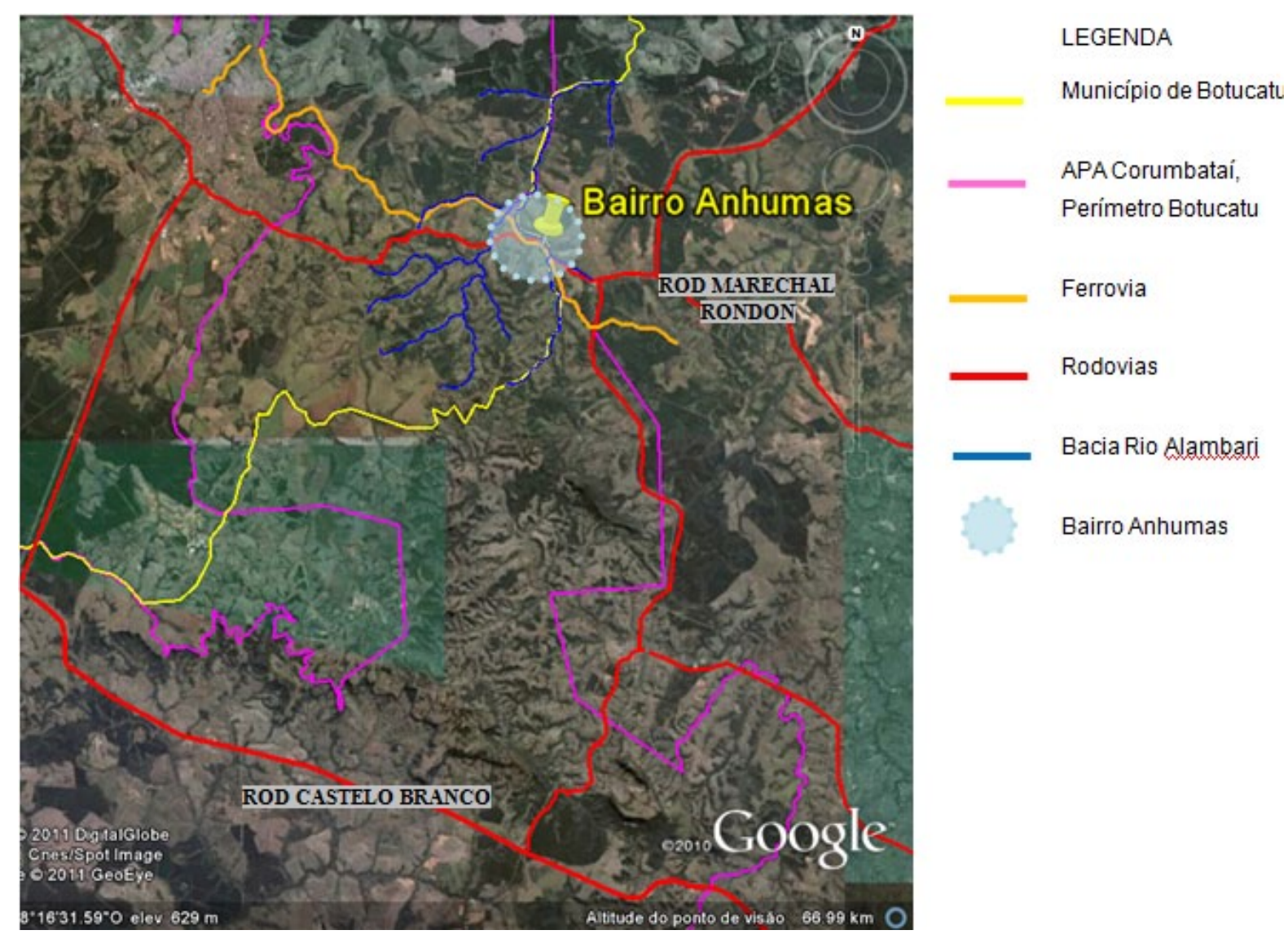

Figura 1: Localização bairro anhumas. Fonte: imagem google earth 2011

O Bairro surgiu às margens da Estação César Neto, segundo Ralph Mennucci Giesbrecht em seu site sobre Estações Ferroviárias no Brasil, a estação pertence à linhatronco da Sorocabana no trecho entre Juquiratiba e Botucatu inaugurada em 1952, funcionou como transporte de passageiros até 1998 e hoje a estação está em péssimo estado.

A linha-tronco ferroviária da Sorocabana serviu de entreposto comercial para o Noroeste, Alta Sorocabana, Paulista e Norte do Paraná, desempenhou importante papel na ocupação do território paulista até que a retração econômica de 1929 que determinou seu estacionamento, gerando um grande impacto em toda a região.

O bairro é formado por cerca de seis quadras e com lotes grandes, residências, de bom padrão construtivo de alvenaria, com energia elétrica, saneamento básico, asfalto sem drenagem e calçadas irregulares (Fig. 02). 


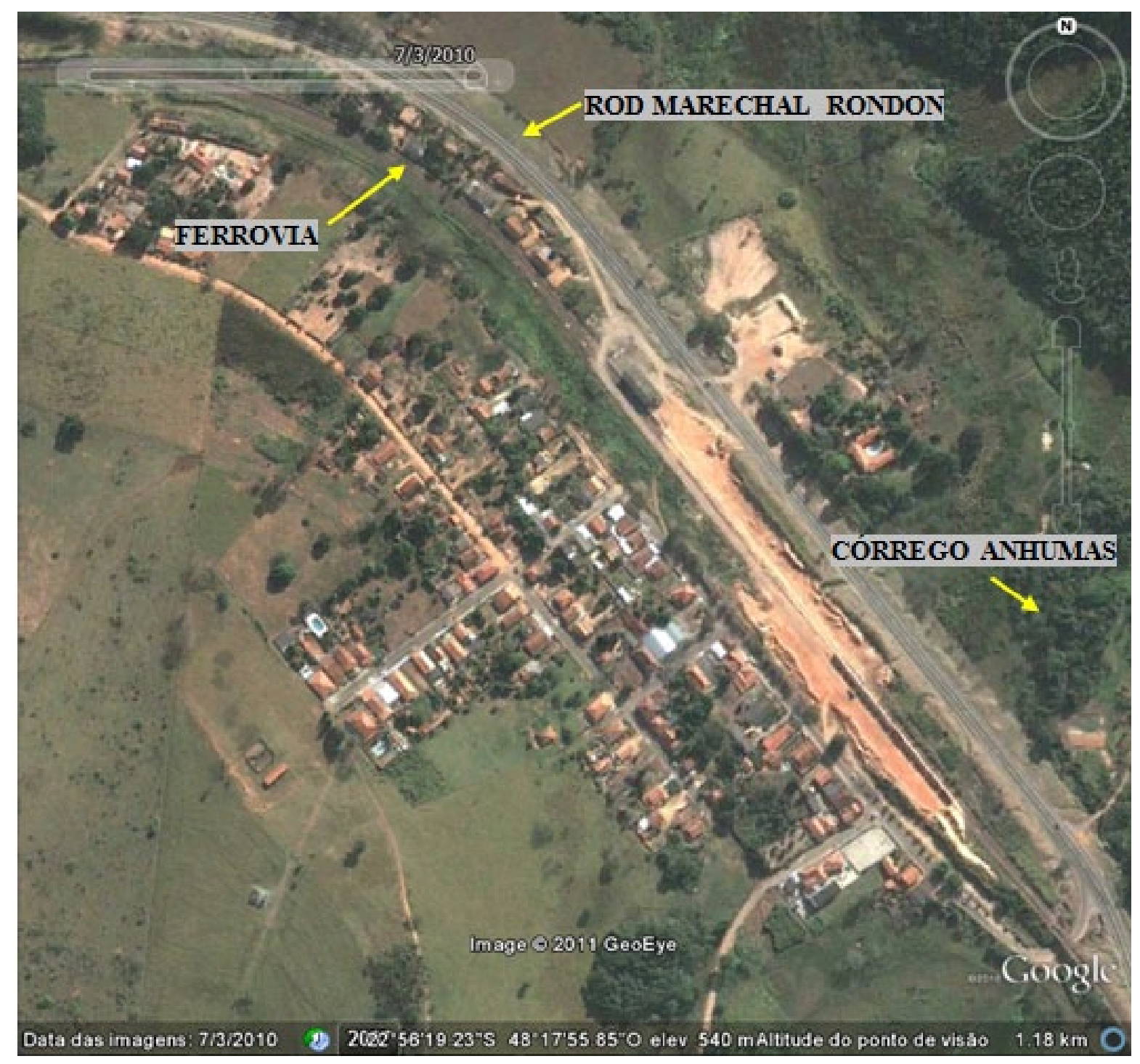

Figura 2: Bairro anhumas. Fonte: imagem google earth 2011.

A comunidade conta com equipamentos públicos como escola, unidade básica de saúde, unidade de tratamento de água, praça e brinquedos infantis com a Igreja de Nossa Senhora Aparecida (Fig. 03 a 06).

Entre as atividades agrícolas do entorno de maior relevância, encontram-se a plantação de pinus, eucalipto, café, confinamento de gado, indústria de ração e áreas de pastagens (Fig. 07 a 12). 


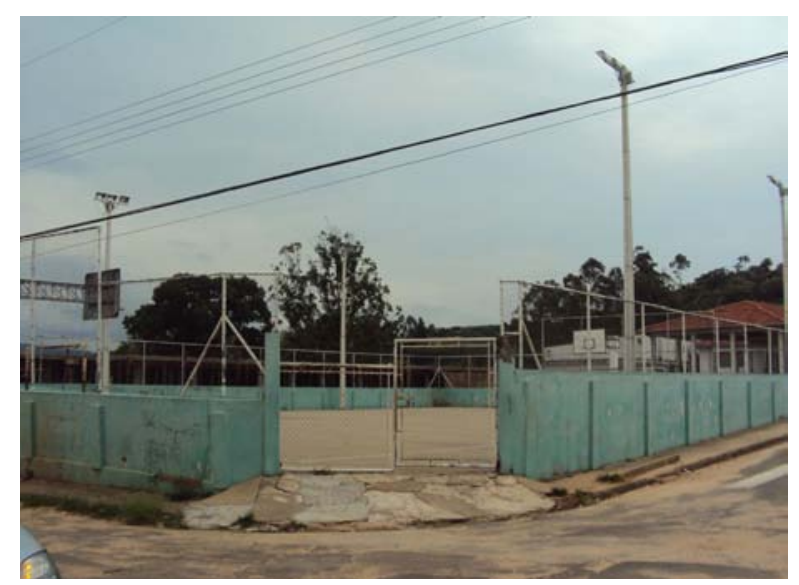

Figura 3: Escola. Foto: ELIANA HOSOKAWA 2011

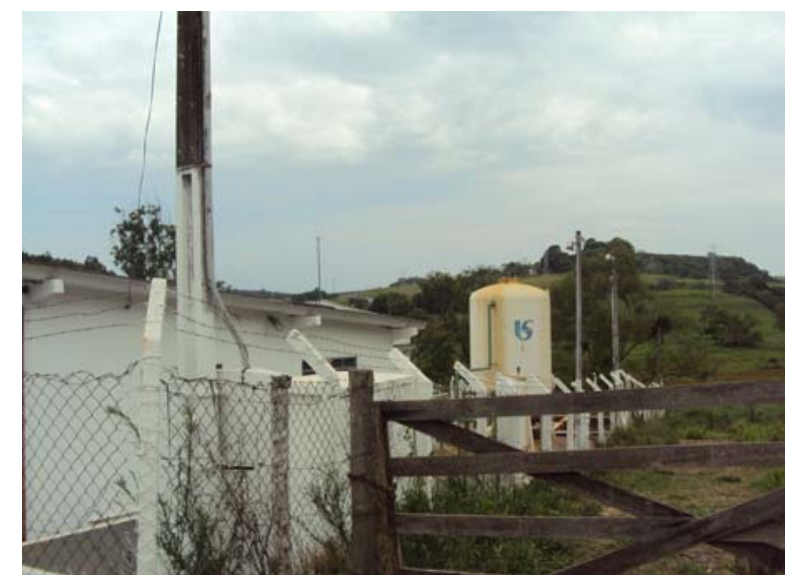

Figura 5: Estação de tratamento. Foto: ELIANA HOSOKAWA 2011

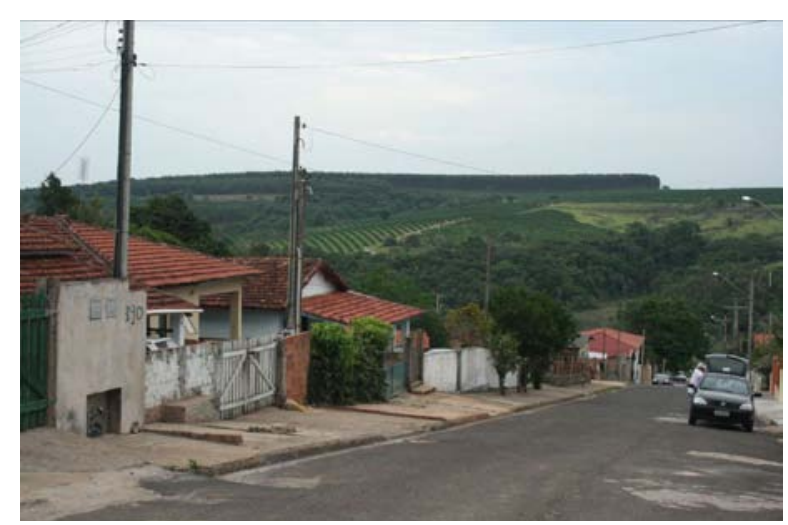

Figura 7: Plantação de Pinus. Foto: ELIANA HOSOKAWA 2011

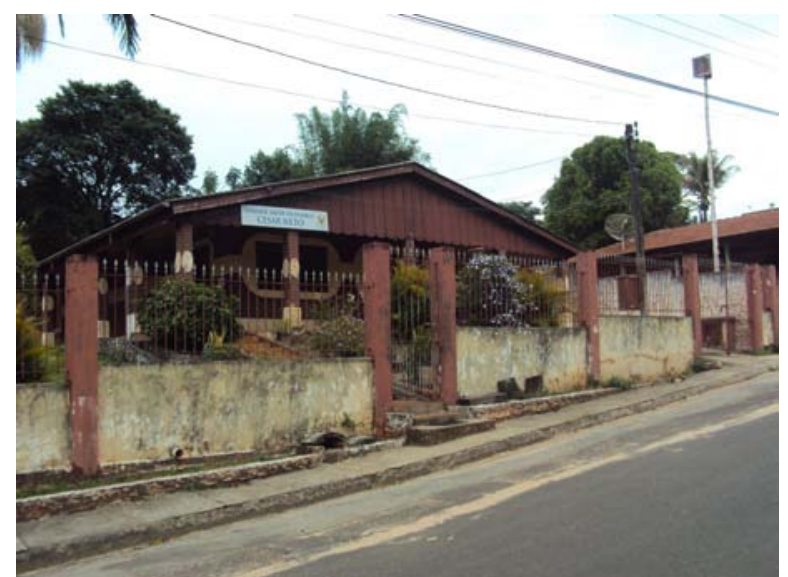

Figura 4: Unidade básica de saúde.

Foto: ELIANA HOSOKAWA 2011

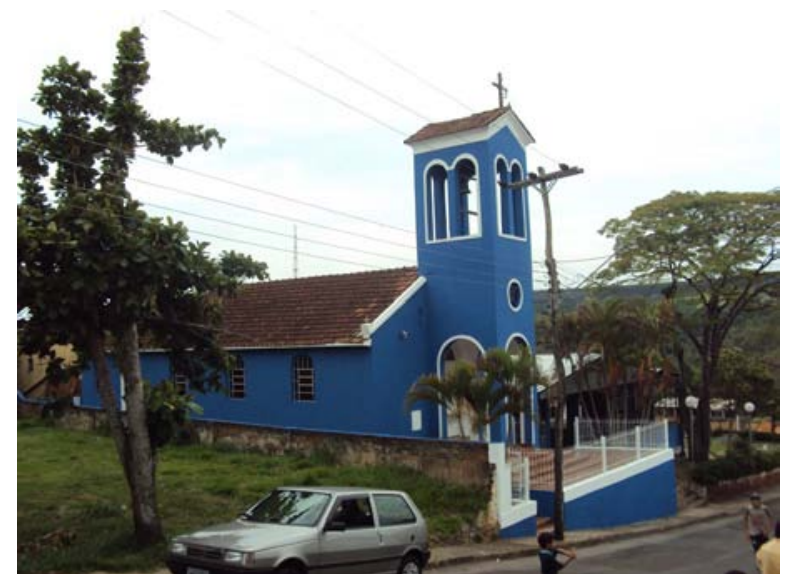

Figura 6: Igreja Nossa Senhora Aparecida. Foto: ELIANA HOSOKAWA 2011

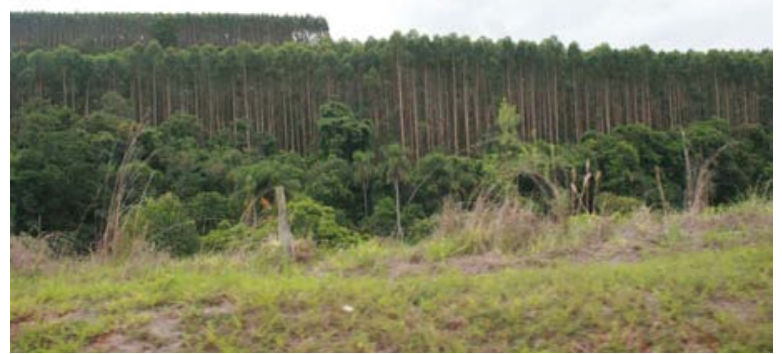

Figura 8: Plantação de Eucalipito. Foto: PATRÍCIA LIMA 2011 


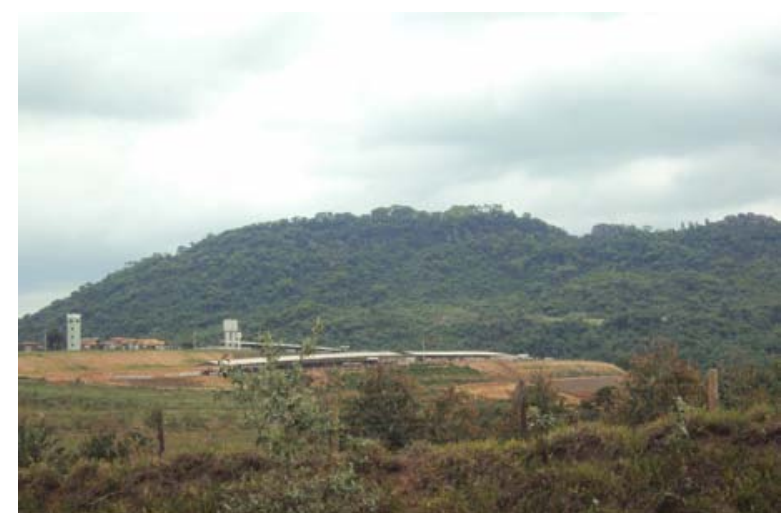

Figura 9: Confinamento de gado. Foto: ELIANA HOSOKAWA 2011

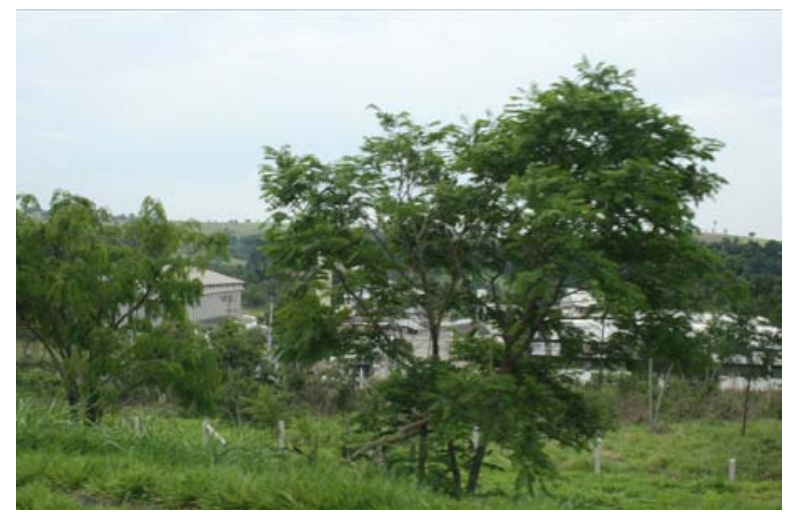

Figura 11: Indústria de ração. Foto: PATRÍCIA LIMA 2011

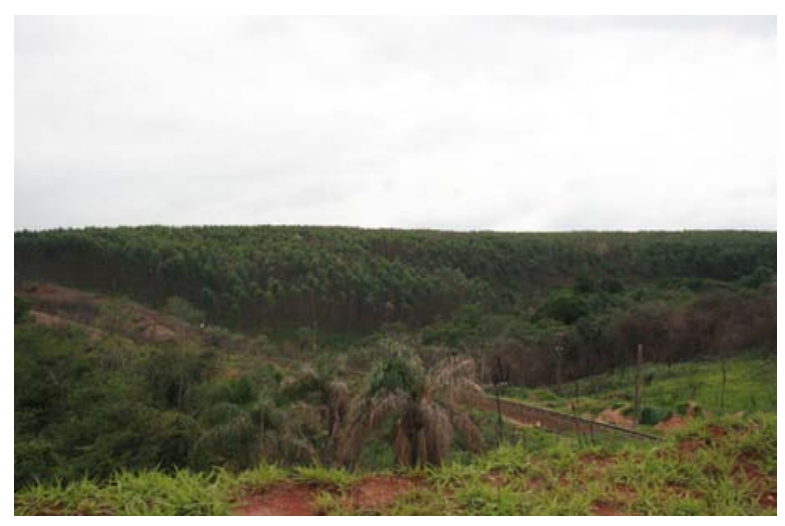

Figura 10: Plantação de café. Foto: PATRÍCIA LIMA 2011

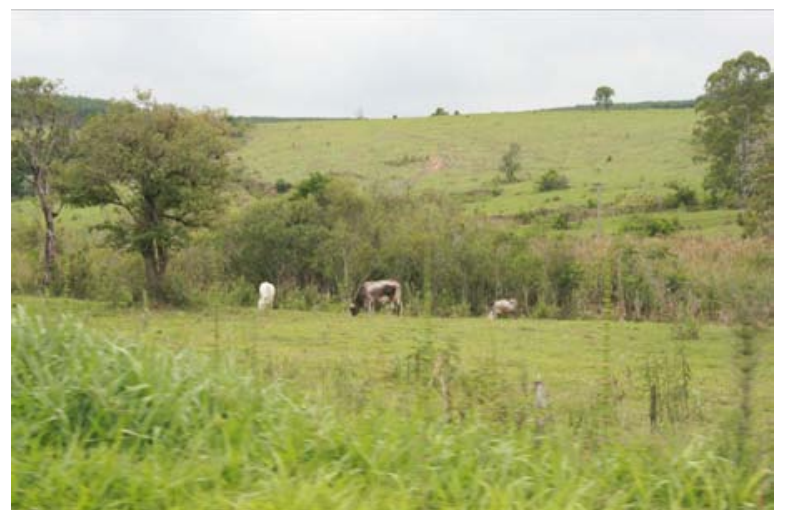

Figura 12: Área de pastagem. Foto: PATRÍCIA LIMA 2011

\section{BAIRRO DE ANHUMAS NA APA CORUMBATAÍ, BOTUCATU E TEJUPÁ - PERÍMETRO BOTUCATU}

A Área de Proteção Ambiental (APA) Corumbataí, Botucatu e Tejupá foi criada em 1983, através do Decreto Estadual no 20.960, tendo como intuito proteger, dentre outros elementos, atributos como as Cuestas Basálticas, Morros Testemunhos das feições geomorfológicas locais, exemplares significativos da flora e fauna, o Aquífero Guarani e o Patrimônio Cultural da região (Fig. 13).

O perímetro Botucatu engloba parte dos municípios da região administrativa de Sorocaba: Angatuba, Avaré, Bofete, Botucatu, Guareí, Itatinga, Pardinho, São Manuel e Torre de Pedra, perfazendo um total de 215.615,1 ha . 
A APA pertence às Unidades de Gerenciamento de Recursos Hídricos (UGRHI) do Estado de São Paulo, encontram-se inserida na UGRHI 10 (Tietê/Sorocaba), UGRHI 13 (Tietê/Jacaré), UGRHI 14 (Alto Paranapanema) e UGRHI 17 (Médio Paranapanema). As principais vias de acesso a APA são as Rodovias Castelo Branco e a Rodovia Marechal Rondon.

Outro ponto que merece grande destaque é o fato da APA Botucatu estar localizada em uma zona de transição entre o bioma da Mata Atlântica e Cerrado, estes dois biomas são os predominantes no Estado de São Paulo. O bioma Mata Atlântica ocupa a maior parte do território estadual, enquanto que o bioma Cerrado, localiza-se no centro do estado.

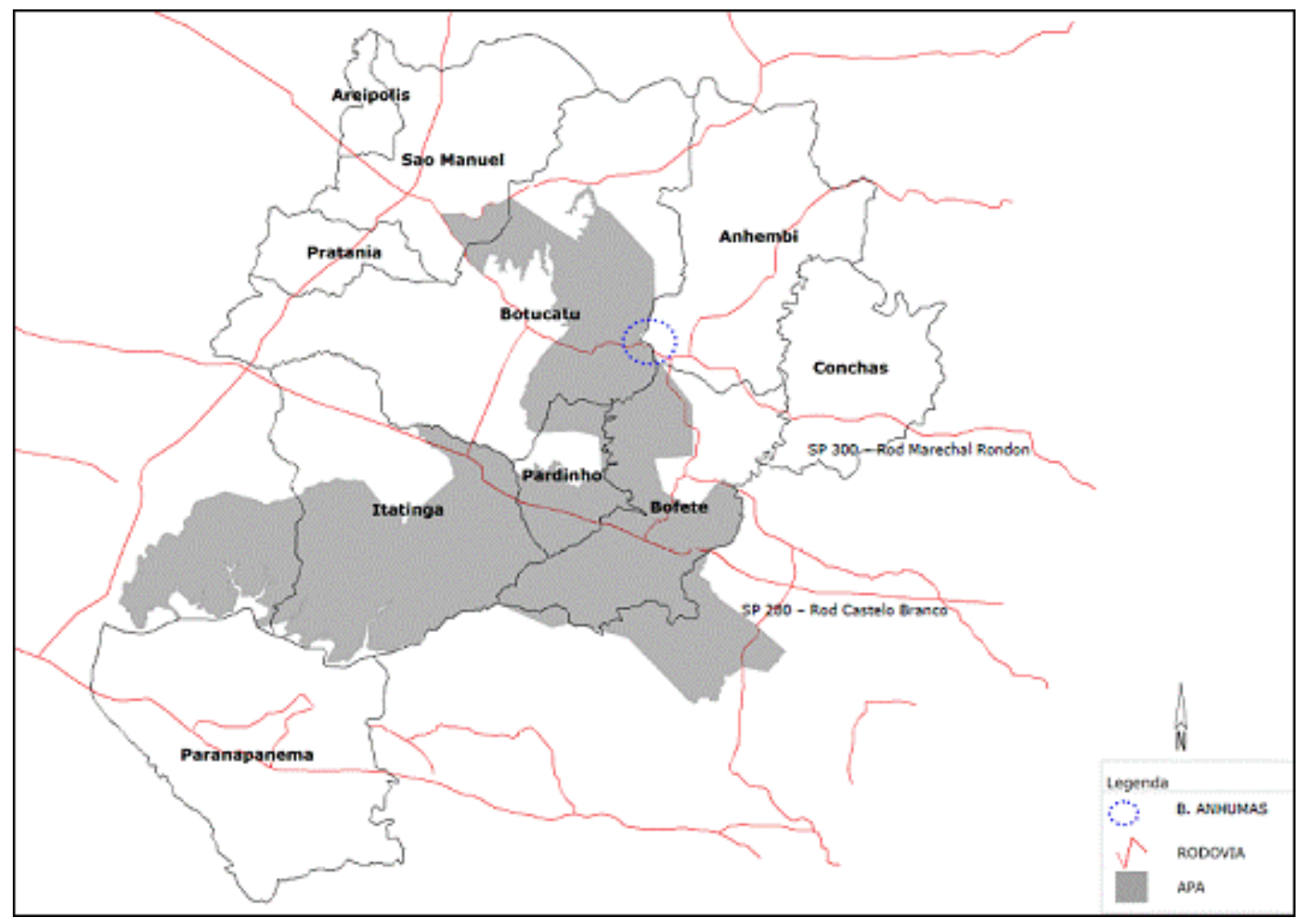

Figura 13: APA Corumbataí, Botucatu e Tejupá, perímetro Botucatu. Fonte: plano de manejo APA Corumbataí, Botucatu e Tejupá. Organizado por Eliana K. Hosokawa. 


\section{BAIRRO DE ANHUMAS NO PLANO DE MANEJO DA APA CORUMBATAÍ, BOTUCATU E TEJUPÁ}

O Plano de Manejo vem sendo utilizado no Brasil desde a década de 1970 como instrumento de planejamento, embora tenha sido legalmente reconhecido em 2000 no contexto do Sistema Nacional de Unidades de Conservação (SNUC).

Após a instituição do SNUC, o Plano de Manejo passou a ser o documento orientador de todas as atividades a serem desenvolvidas nas unidades de conservação, sendo obrigatória a elaboração do Plano de Manejo das unidades de conservação.

Desta forma, os Planos de Manejo constituem o principal instrumento de gestão das UC, devendo definir o zoneamento da área abrangida e estabelecer os Programas de Gestão a partir da realização de análises e diagnósticos dos elementos do meio físico, biótico e antrópico, num processo de planejamento integrado e participativo (Fig. 14). O zoneamento da APA Botucatu teve como objetivo o ordenamento do uso e ocupação do solo, a conservação das formações geológicas e dos ecossistemas associados, dos recursos hídricos superficiais e subterrâneos e a proteção do patrimônio arqueológico (Fig. 15).

A demarcação das zonas foram resultados dos diagnósticos do uso do solo, extraindo dele os aspectos mais relevantes para sua definição. O uso do solo predominante no Bairro de Anhumas é pastagem e esta na ZCH2 - Zona de Conservação Hídrica 2 que compreende as áreas onde há afloramento do Aquífero Guarani em terrenos de declividade acentuada e com alta fragilidade erosiva. Nestas áreas predomina o processo de escoamento superficial em detrimento da infiltração da água no solo.

As ações relacionadas à ZCH2 visam minimizar processos erosivos, assoreamento dos corpos hídricos, contaminação das águas superficiais e do Aquífero Guarani e pastoreio em áreas de vegetação nativa. 

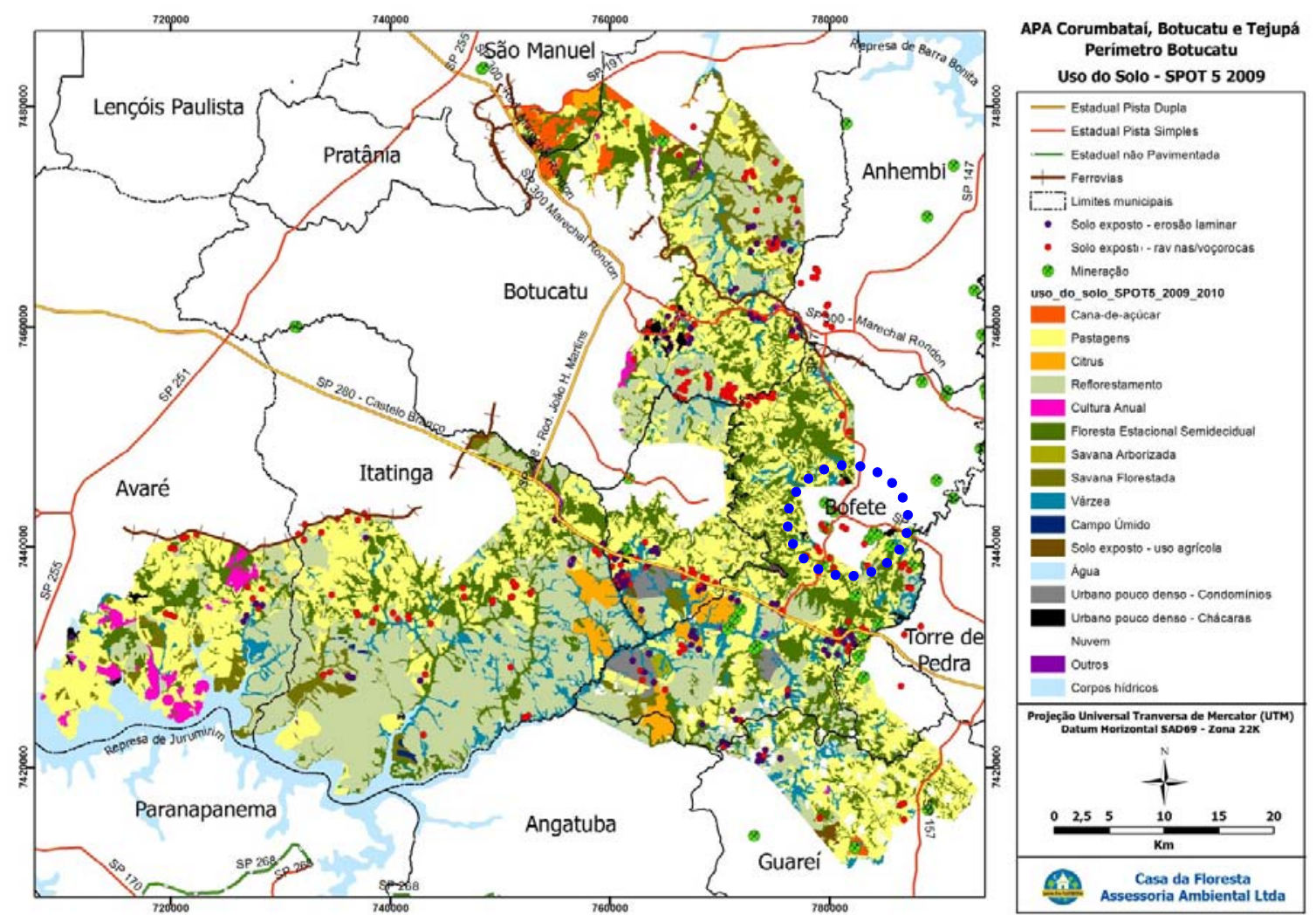

Figura 14: Plano de manejo APA Corumbataí. Botucatu e Tejupá. Fonte: mapa uso do solo.

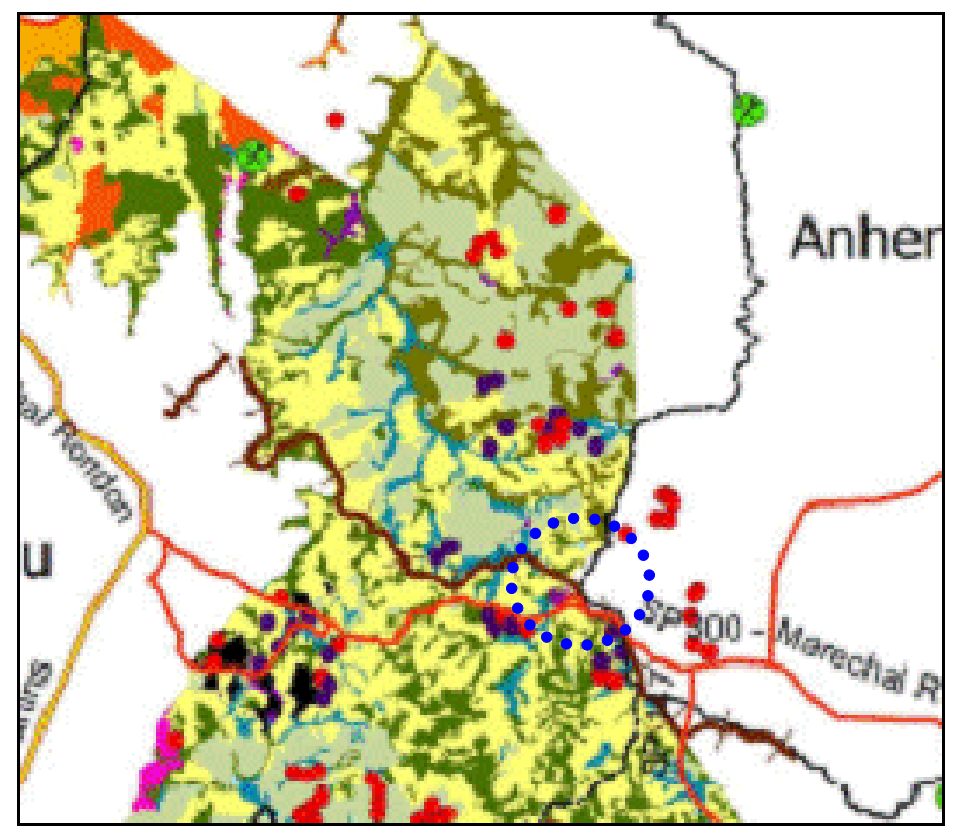

\section{LEGENDA}

$\because \quad$ Bairro Anhumas

Pastagens 


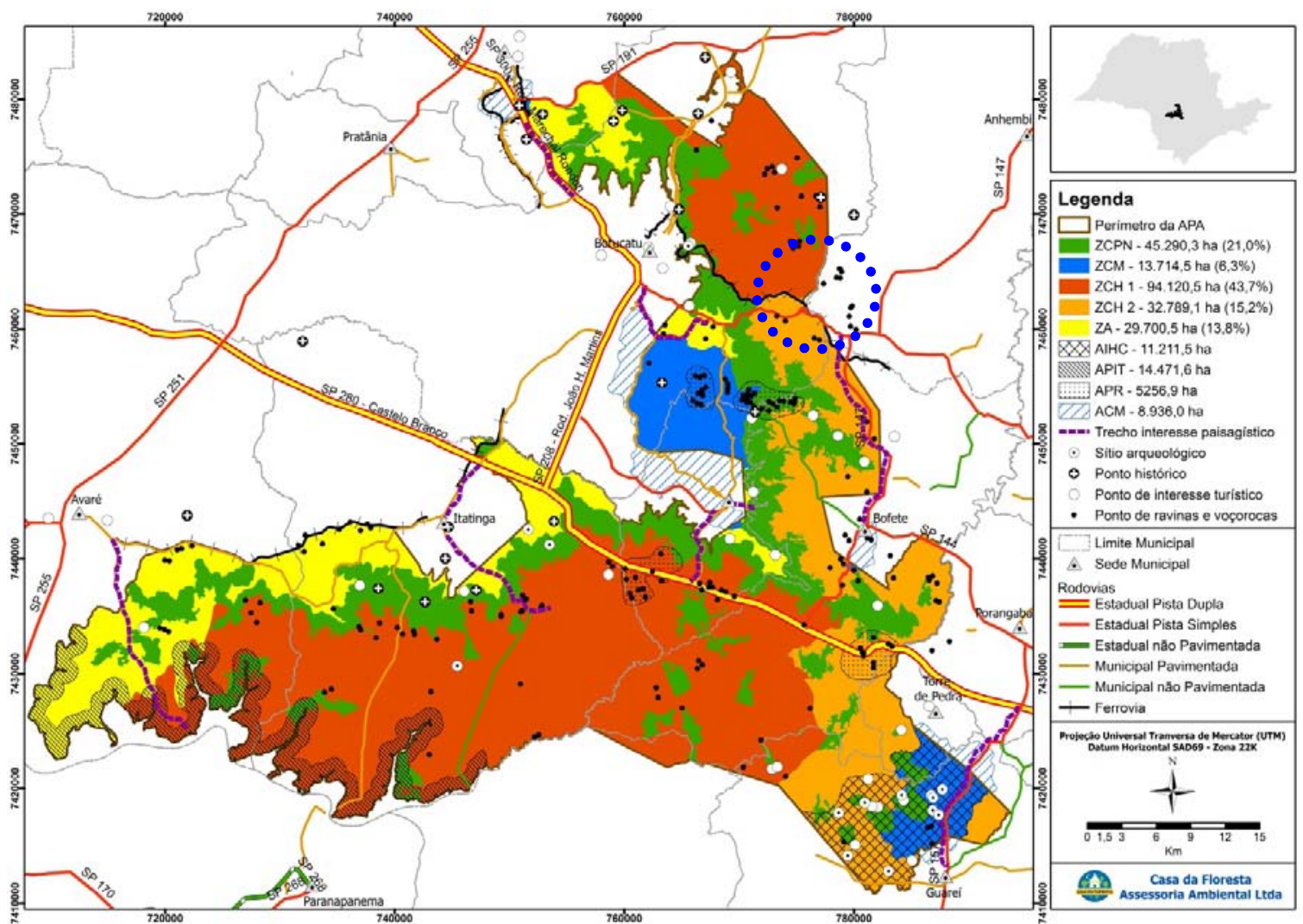

Figura 15: Plano de manejo APA Corumbataí. Botucatu e Tejupá. Fonte: mapa de zoneamento. Bairro de Anhumas no Aquífero Guarani.

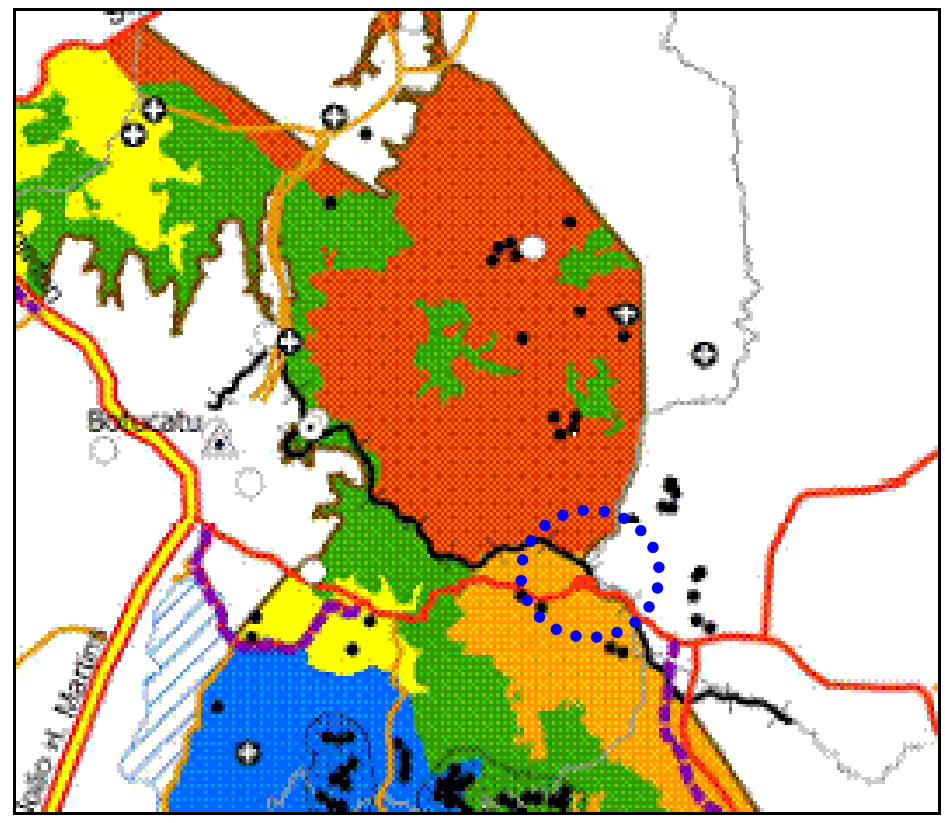

\section{LEGENDA}

$\because \quad$ Bairro Anhumas

PZCH2 - Zona de

Conservação Hídrica 2 


\section{BAIRRO DE ANHUMAS NO AQUÍFERO GUARANI}

Levando-se em consideração que a APA encontra-se quase que totalmente inserida na área de afloramento do Aquífero Guarani (Fig. 16), torna-se essencial o planejamento e o monitoramento das atividades de uso do solo frente sua influência direta sobre a qualidade das águas subterrâneas.

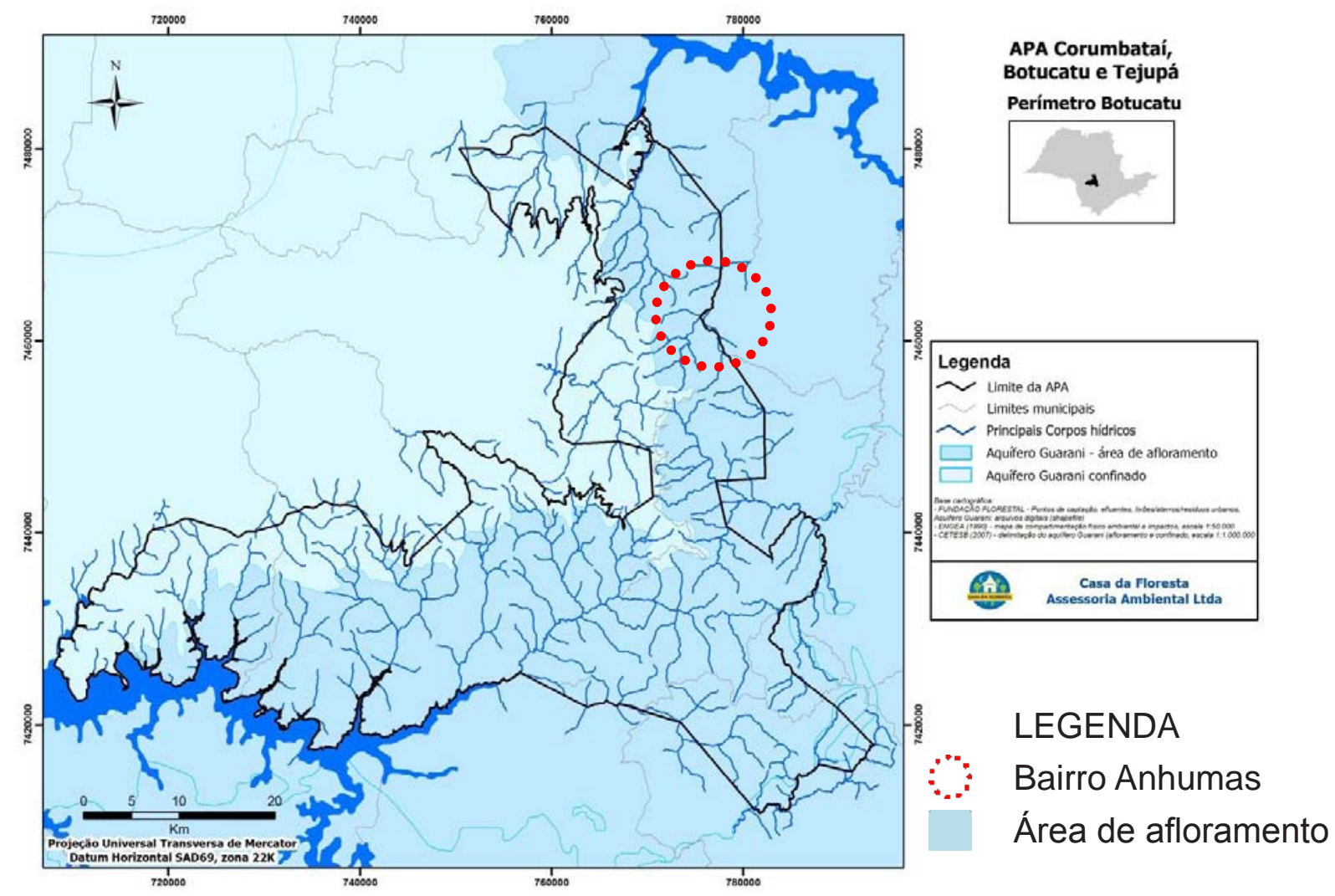

Figura 16: Área de afloramento do aquífero. Fonte: aquífero - plano de manejo APA Corumbataí, Botucatu e Tejupá.

O Aquífero Guarani é compartilhado com a Argentina, Paraguai e Uruguai, que compõem o Sistema de águas transfronteiriças ${ }^{1}$, caracterizando uma dinâmica de grande complexidade, pois envolve mais que um país e suas respectivas políticas, cultura, geografia, organização institucional, entre outros aspectos.

1 A gestão transfronteiriça existe pela utilização de águas de domínio comum, entre diferentes países. É motivada por diversos fatores, tais como, o crescimento da população de usuários da mesma água, o uso inadequado do solo, diferentes padrões utilizados para o consumo de água, o impacto da contaminação hídrica, a crise de governabilidade da água, o incremento de atividades econômicas, entre outros (BROCH, 2008). 
Foi criado em 2003, o Projeto de Proteção Ambiental² e Desenvolvimento Sustentável do Sistema Aquífero Guarani (SAG). O Projeto definiu áreas pilotos em quatro municípios dos países envolvidos, segundo a criticidade de suas áreas em função dos conflitos relacionados às características hídricas, ao uso do solo e ao aproveitamento do aquífero, e aos riscos de contaminação (BROCH, 2008).

Nas diferentes regiões onde ocorre o Aquífero Guarani, seja no Brasil, Argentina, Paraguai ou Uruguai, a diversificação de uso e de manejo tem sido muito grande em suas áreas de recarga direta, exibindo porções com uso agrícola intensivo, pastagens, áreas ainda cobertas por vegetação nativa e áreas degradadas (GOMES, 2006). Essas situações são igualmente importantes na área do Bairro de Anhumas, principalmente observando estudos que constatam que o fluxo de água na camada geológica que compõe o aqüífero é mais lento do que se imaginava anteriormente.

"O risco é indissociável da política. A forma como se dá a organização do território, a distribuição dos bens e o uso dos recursos naturais pressupõem uma aposta do poder público sobre o futuro" (VILLAR, 2009).

Ribeirão Preto foi a cidade do Brasil definida para área piloto ${ }^{3}$ onde foram estabelecidas diretrizes de utilização sustentável e proteção do aquífero Guarani, tendo dentre as premissas gerais o controle de disposição de resíduos e efluentes, sobretudo na área de afloramento e diretrizes que devem considerar o Zoneamento do Uso do Solo e Ocupação do Solo, definindo diretrizes para a Zona Rural e Urbana, que podem ser ressaltadas na situação do Bairro Anhumas, por se encontrar em importante área de recarga do aqüífero e em condição de mudança de zoneamento proposto no Plano Diretor de Botucatu e no Plano de Manejo da APA.

\footnotetext{
2 Com o objetivo de apoiar os países envolvidos na elaboração e implementação coordenada de uma proposta de modelo institucional, legal e técnico comum, para a preservação e o gerenciamento do Sistema Aquífero Guarani.
}

3 II CONGRESSO AQUíFERO GUARANI RIBEIRÃO PRETO (SP) - 04 a 07 de novembro de 2008 (http://www.ambiente.sp.gov.br/2_con_aqu_gua_02_02_09.pdf). 
Para a Zona Rural, foram considerados a vulnerabilidade natural da área, a aptidão agrícola (relevo, solo) e o modelo de produção agrícola. Para a Zona Urbana, foram considerados o parcelamento da ocupação do solo, o controle de fontes potenciais de poluição, o controle de captações e o controle de impermeabilização do solo.

\section{BAIRRO DE ANHUMAS NO PLANO DIRETOR BOTUCATU}

O Plano Diretor de Botucatu - Lei Complementar 483 de 2007 têm por fim realizar o pleno desenvolvimento das funções sociais do Município e da propriedade, o uso socialmente justo e ecologicamente equilibrado de seu território, de forma a assegurar o bem-estar de seus habitantes e democratizar o acesso a bens e serviços, tendo entre as diretrizes: promoção da qualidade do ambiente, preservação da identidade cultural, promoção do cumprimento da função social da propriedade, potencialização dos recursos naturais mediante o planejamento conjunto de sua utilização e desenvolvimento sustentável.

Para o recorte proposto neste artigo, salientamos a área do Bairro Anhumas pertence à zona de Adensamento Prioritário na Zona Rural, determinada na Carta I. A Lei propõe que as áreas que não tiverem pelo menos $20 \%$ de sua área cultivada e/ou plantada com espécies nativas, reserva legal e APP averbadas, serão consideradas subutilizadas e terá prazo para se adequar estabelecendo cultivos ou apresentando projeto de parcelamento na Prefeitura Municipal (Fig. 17).

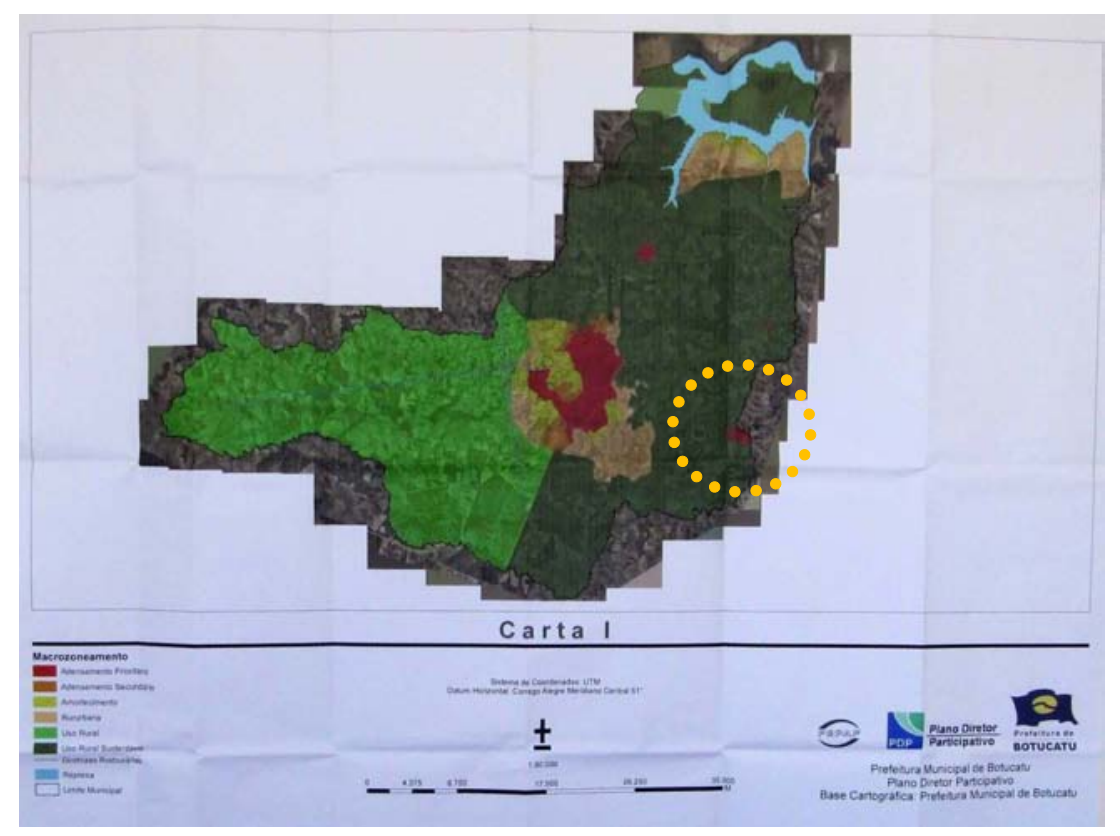

Figura 17: Plano diretor com destaque para o bairro Anhumams. Fonte: carta I - plano diretor do município de Botucatu.

\section{LEGENDA}

Bairro Anhumas

Adensamento

prioritário 


\section{BAIRRO ECOLÓGICO E DESENVOLVIMENTO SUSTENTÁVEL}

O Bairro Anhumas se destaca pela complexidade da área rural em que está inserido, ambientalmente protegido pela APA e para atender a uma proposta de adensamento que aponta para mudanças em seu modelo de desenvolvimento com desafios significativos de adaptação dos moradores locais, agricultores familiares e regionais, alguns temas devem ser abordados para que sejam minimizados os impactos que serão provocados pelas mudanças propostas para o local.

O desenvolvimento sustentável, através da harmonia e da racionalidade entre homem e natureza, promove objetivos comuns nos grupos envolvidos no seu meio e na busca do bem estar adequado a todos e adaptado à realidade local. Isso requer uma mudança de foco do desenvolvimento rural e cria uma necessidade de revisão na forma da organização social, na definição de seu limite de produção, consumo e ocupação.

Desta forma torna-se possível integrar as políticas agrícolas e ambientais no Bairro Anhumas dentro do desenvolvimento sustentável, que promovam mudanças nos modelos produtivos, econômicos e sociais através de mecanismos de regulação direta, fundamentado na disseminação de experiências locais, que desestimulem a exclusão social, incorporando-as ao processo produtivo adotado.

Essa integração viabiliza ação política na elaboração de estratégias de desenvolvimento fundamentadas nos eixos locais e regionais, resgatando conhecimentos locais, práticas de manejo e proteção ambiental.

Uma APA tem como objetivos básicos proteger a diversidade biológica, disciplinar o processo de ocupação e assegurar a sustentabilidade do uso dos recursos naturais, buscando compatibilizar o uso dos recursos naturais e a conservação ambiental com a ocupação humana.

Para um modelo de gestão eficiente que permita o desenvolvimento sustentável, levando em conta a relação do território e sua população e o vínculo desta população com os recursos naturais remete-nos a pensar em iniciativas de formação de consciência ambiental. 
Nesse modelo, é possível conciliar oportunidades de trabalho, geração de renda, consciência ambiental, conservação dos recursos naturais e sustentabilidade. A população é beneficiada com a produção agrícola, equipamentos básicos de infra-estrutura. A fauna e flora podem ser protegidas, respeitando os assentamentos fundiários, os recursos hídricos, forte componente da preocupação da conservação, protegido pelo uso adequado do solo.

A proposta desse modelo demonstra a capacidade do adensamento nesta área da APA, proposto pelo Plano Diretor de Botucatu, entendendo o novo foco da sustentabilidade na intervenção do território. Importante eixo viário (Fig.18), industrial e tecnológico existentes, polarizado no município de Botucatu, propicia o crescimento proposto, ainda que em contraste com a ocupação atual, baseada em atividades agrícolas (Fig. 19).

Situações atuais no Bairro Anhumas colaboram para o crescimento da degradação da área de grande fragilidade ambiental, com impactos que precisam ser monitorados com ações urgentes. O assoreamento do córrego Anhumas, por exemplo, já é possível ser observado em função de atividades de transporte de areia (Fig.20) e da falta de drenagem nas vias locais (Fig. 21).

A linha férrea é utilizada atualmente para transporte de areia para fins particulares. Existe um enorme volume de areia armazenado indevidamente a céu aberto às margens da linha férrea (Fig. 22), o que resulta no espalhamento do material no bairro e na rodovia (figs. 23 a 25 ).

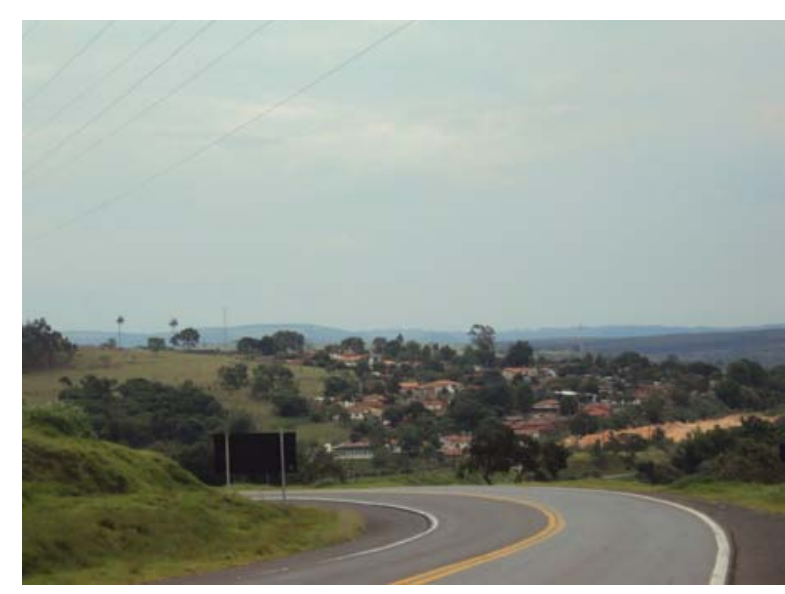

Figura 18: Bairro Anhumas visto da Rod. Marechal Rondon. Foto: PATRÍCIA LIMA 2011

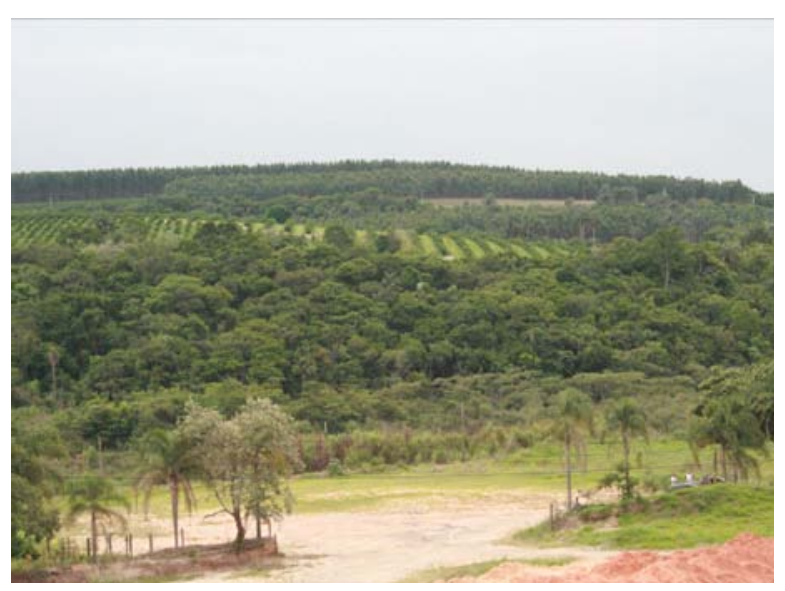

Figura 19: Uso do solo no entorno do bairro. Foto: PATRÍCIA LIMA 2011 


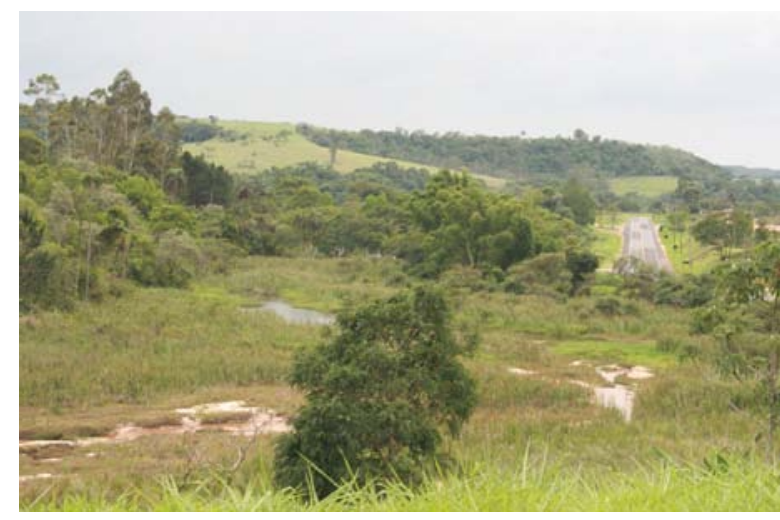

Figura 20: Assoreamento do córrego Anhumas. Foto: PATRÍCIA LIMA 2011

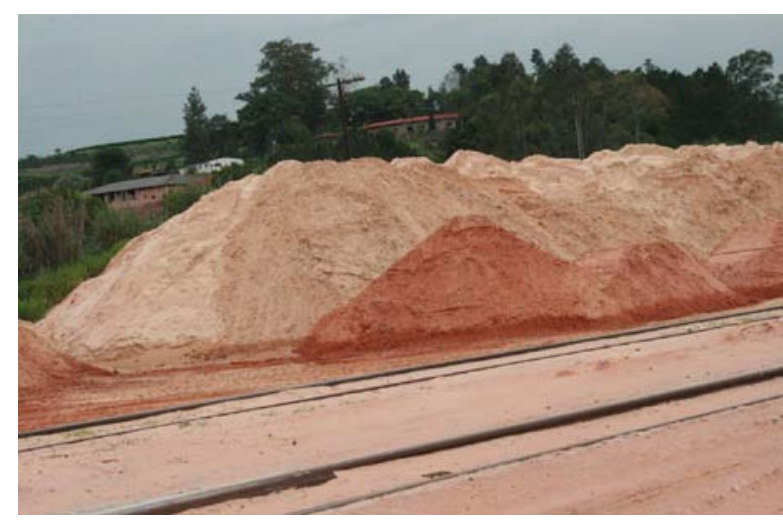

Figura 22: Trilho coberto de areia. Foto: PATRÍCIA LIMA 2011

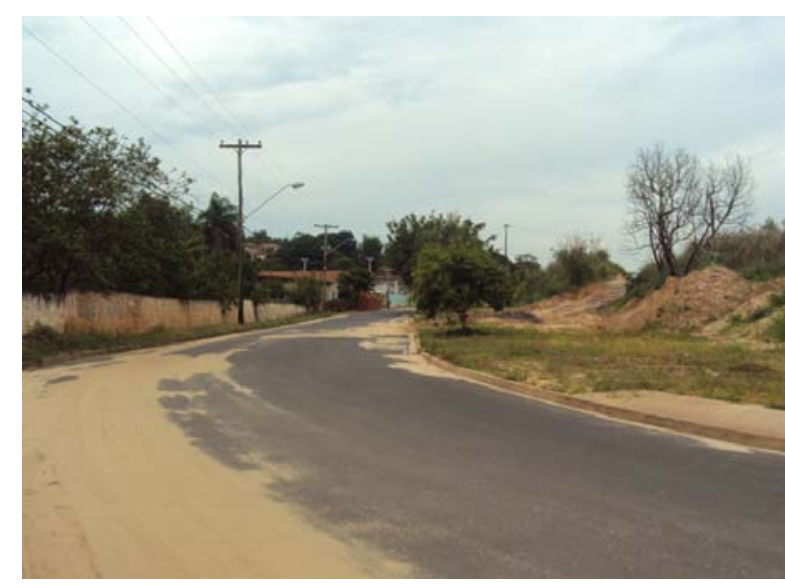

Figura 24: Espalhamento de areia sentido bairro. Foto: PATRÍCIA LIMA 2011

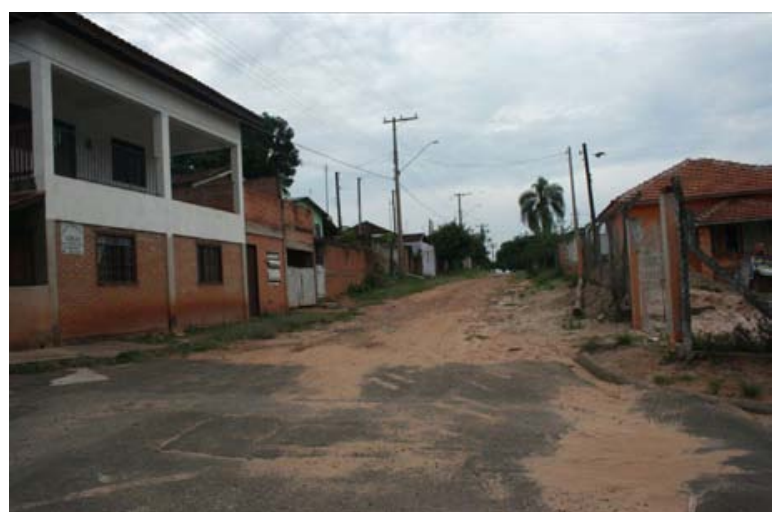

Figura 21: Logradouros sem drenagem. Foto: PATRÍCIA LIMA 2011

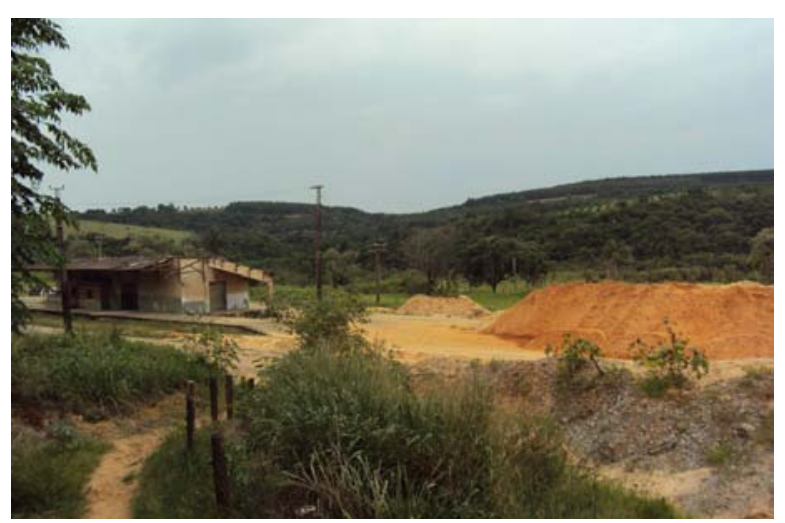

Figura 23: Estação ferroviária em estado precário. Foto: PATRÍCIA LIMA 2011

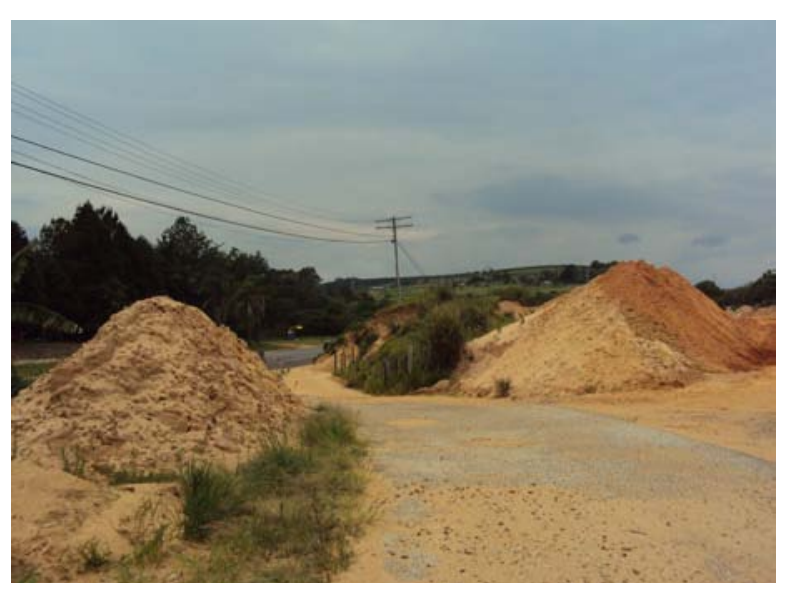

Figura 25: Espalhamento de areia sentido Marechl Rondon. Foto: PATRÍCIA LIMA 2011 
Em 2007, a ATER - Atividades de Assistência Técnica e Extensão Rural- (INSTITUTO GIRAMUNDO/UNESP-BOTUCATU/MDA-SAF) concluiu o trabalho em Botucatu evidenciando o caráter expressivo das atividades agropecuárias e da aceleração fundiária que tem contribuído para um forte êxodo rural, desfavorecendo o sistema familiar de exploração agrícola e sua reprodução sócio-cultural.

Em paralelo, salientaram que a cidade vem desenvolvendo práticas de estilos ecológicos de agricultura refletida pelos trabalhos de organizações da sociedade civil, coordenado pela ATER. O Bairro do Povoado de Anhumas é considerado importante do ponto de vista ambiental, social e cultural para o desenvolvimento rural sustentável da região, por entenderem que essa comunidade cria a conexão com os agricultores da região e busca estabelecer um modelo de ecodesenvolvimento, estratégico para em conjunto, diminuírem as pressões sobre os recursos naturais (BERGAMO, 2007).

Na percepção da comunidade de Anhumas, o principal problema enfrentado é a diminuição das reservas de água na superfície e o empobrecimento do solo e das condições para a produtividade agrícola, com destaques nas lavouras de cana-de-açúcar, citrus, café, culturas florestais como pinus e eucalipto, além de intensa produção de bovino de corte e de leite. A região é atualmente coberta de pastagens em estágios avançados de degradação, devido à pecuária extensiva, atividade predominante no local.

A análise de Agro ecossistemas ${ }^{4}$ foi à metodologia aplicada, oferecendo diversas técnicas visuais de fácil aplicação para que os agricultores e técnicos pudessem conjuntamente, iniciar a análise sistêmica das propriedades, e entenderem o significado de agro ecossistemas como um todo - um conjunto de subsistemas de produção que se relacionam-. Os trabalhos envolvendo grupo de pessoas demonstram ser possível um desenvolvimento sustentável, devolvendo a vida coletiva integrada à natureza.

\footnotetext{
4 Agroecologia É uma ciência que fornece os princípios ecológicos básicos para o estudo e tratamento de ecossistemas tanto produtivos quanto preservadores dos recursos naturais, e que sejam culturalmente sensíveis, socialmente justos e economicamente viáveis, proporcionando assim, um agro ecossistema sustentável. A abordagem agro ecológica da produção busca desenvolver agro ecossistemas com uma dependência mínima de insumos agroquímicos e energéticos externos (Coordenadoria de Assistência Técnica Integral - CATI).
} 
O exemplo do Bairro do Povoado de Anhumas, com a preocupação da pequena produção familiar oferece alternativas apropriadas para a melhoria dos sistemas produtivos, que preservem o solo, as águas subterrâneas e a economia familiar, sem investimentos elevados e sem utilização de agroquímicos. Surge um redesenho dos sistemas de produção que minimizam a necessidade de insumos externos ao local, propiciando a visão sistêmica proposta.

Desde 2008 o centro de pesquisas LABVERDE da Faculdade de Arquitetura e Urbanismo da Universidade de São Paulo criou o selo LABVerde destinado à avaliação e certificação ambiental de empreendimentos e projetos com ênfase em Localização Sustentável. A certificação do selo LABVerde está sendo aplicada em quatro níveis que classifica os projetos quanto ao desenvolvimento, eficiência, qualidade e excelência.

Os critérios de pontuação baseiam-se nos princípios da Agenda 21 e do Protocolo de Kioto e percorrem várias escalas de atuação através de parâmetros das áreas de Planejamento e Gestão Ambiental na escala regional, Desenho Ambiental nas escalas urbana e setorial e Projeto Sustentável na escala local.

A Localização Sustentável exige pensar globalmente o processo de planejamento em larga escala em busca de um impacto positivo na proteção ambiental, pois práticas regionais e urbanas podem incorporar um pensamento ecológico fundamentado na comunidade, na economia e na sustentabilidade ambiental.

A comunidade de Anhumas não se enquadra nos critérios de pontuação do Selo LABVerde, porém possui grande potencial de Localização Sustentável que pode ser desenvolvido por meio de diretrizes de um Projeto Sustentável que contemplem os critérios de pontuação do Selo LABVerde em escala local, como: eficiência de energia nos edifícios, captação de águas pluviais e redução do uso da água, reuso de edifícios e adaptação de reuso, descontaminação na recuperação de solos degradados, coleta seletiva do lixo. 


\section{CONSIDERAÇÕES FINAIS}

A dinâmica do uso da terra tem importante significado para adaptação às mudanças do desenvolvimento proposto para a região de Botucatu e importante papel na mitigação de impactos decorrentes. A complexidade desta região, tanto ambiental quanto social e econômica requer práticas em diferentes níveis de atuação.

O estudo presente mostra a importância de esferas setoriais e regionais para que se possa atuar em âmbito local. No entanto, no processo de criação de diretrizes ainda são tímidas as ações conjuntas. Na análise das diretrizes do Plano Diretor de Botucatu e do Plano de Manejo da APA, percebem-se algumas incoerências em relação ao uso do solo que refletem esta falta de sintonia.

O Plano de Manejo da APA proíbe qualquer intervenção, alteração, desenvolvimento de atividades ou modalidades de utilização do Plano de Manejo da APA e seus regulamentos, no entanto o Plano Diretor de Botucatu não respeita integralmente tais diretrizes.

O Plano de Manejo tem gestão regional dos municípios que compõe a APA e mesmo formando uma única área, ainda são as fronteiras administrativas que determinam decisões, ao invés da definição de parâmetros espaciais para recorte das características contínuas de uma bacia hidrográfica, por exemplo. Ainda é preciso estabelecer parcerias com municípios, instituições e centros de pesquisas para o desenvolvimento do zoneamento ambiental.

As diretrizes de Plano de Manejo da APA devem orientar as atividades a serem desenvolvidas, definindo o zoneamento e estabelecendo programas de gestão com o intuito de proteger as Cuestas Basálticas, Morros Testemunhos e feições geomorfológicas locais. Questões estas alinhadas às diretrizes do macro zoneamento do Plano Diretor que tem como objetivo estabelecer parâmetros adequados de adensamento e uso e ocupação do solo para preservar as áreas de recarga do Aquífero Guarani e regular a os de recursos naturais.

No entanto, é possível observar um conflito de zoneamento quando comparamos o Plano Diretor e o zoneamento do Plano de Manejo. No Plano Diretor o Bairro Anhumas foi identificado como Zona de Adensamento Prioritário na Zona Rural dentro da APA na Zona de Conservação Hídrica 2 - ZCH2 do Plano de Manejo da APA. 
Entendemos a hipótese da gestão compartilhada em diferentes níveis, quando verificamos esforços de projetos conjuntos na experiência entre países para diretrizes na proteção e utilização do aquífero. No Plano de Manejo da APA, que envolve diferentes municípios, enfrentar o desafio de tornar tais territórios instrumentos de planejamento regional, integrando as populações, independente de limites administrativos trará ganho regional expressivo e em escala local, há urgência de ações que propiciem maior controle sobre os impactos do adensamento proposto.

O Bairro Anhumas ainda se encontra em condição de definir diretrizes para um controle do crescimento e desenvolvimento, sabendo ser esta uma área de adensamento prioritário, devendo garantir e melhorar a qualidade dos recursos hídricos e mitigar os vetores de pressão do uso da terra, aproveitando experiências já em andamento e propondo diretrizes aplicáveis a novos modelos sustentáveis.

A hipótese da criação de um Bairro Ecológico dentro da APA em uma área sensível ambientalmente mostra uma oportunidade de um planejamento integrado com múltiplos aspectos, com estratégias de adaptação de uso do solo sustentabilidade, que requerem metodologias que transcendam as visões setoriais isoladas que buscam alcançar um enfoque integral que considere as diferentes escalas.

\section{REFERÊNCIAS BIBLIOGRÁFICAS}

BERGAMO, André; GALDINO, Mariana Cassins; PESTELLI, Mariana Murakoshi; TASSI, Zaria Elisa von Zuben e SILVA, Silvia Pereira da. A construção de um novo extensionista a partir da experiência do projeto piloto de formação de quadros de ATER - INSTITUTO GIRAMUNDO/UNESP-BOTUCATU/MDA-SAF. Trabalho de conclusão do Projeto de Formação de Quadros de Assistência Técnica e Extensão Rural- Ater - SAF/ MDA- Brasil, Botucatu, 2007.

COORDENADORIA DE ASSISTÊNCIA TÉCNICA INTEGRAL - CATI. Disponível em: $<$ http://www.cati.sp.gov.br/new/acervotecnico.php?ID=1> Acesso em 01/11/11.

ESTAÇÕES FERROVIÁRIAS DO BRASIL. Disponível em: <http://www.estacoesferroviarias.com.br/c/cesarneto.htm> Acesso em 17/10/2011. 
SELO LAB-VERDE. Disponível em: <http://www.fau.usp.br/depprojeto/labverde/projetos_04.html> Acesso em 03/10/11.

MODELO DE DESENVOLVIMENTO SUSTENTÁVEL. Disponível em: <http:// www.pratigi.org/portal/index.php?option=com_content\&view=article\&id=1263\&Item id=538> Acesso em 30/10/11.

PIZA, João Fernando Blasi de Toledo. O Tratamento dados as APPs e APA no Plano Diretor Participativo de Botucatu. Disponível em: <http://www.arquitetura.ufc. br/professor/Clarissa\%20Sampaio/2011-1\%20PU-1/etapa\%2002/artigos\%20seminario\%20APP/GT-113-101-20070731161218.pdf> Acesso em 04/10/2011.

PLANO DE MANEJO DA APA CORUMBATAI, BOTUCATU E TEJUPÁ - PERIMETRO BOTUCATU. Decreto Estadual n 23057/2008.

PLANO DIRETOR DE BOTUCATU. Lei Complementar 483 de 2007.

VILLAR, Pilar Carolina. GESTÃO DAS ÁREAS DE RECARGA DO AQUÍFERO GUARANI: O CASO DO MUNICÍPIO DE RIBEIRÃO PRETO, SÃO PAULO. São Paulo, 2008. 